\title{
Nuclear magnetic resonance - from molecules to man
}

\section{Journal Article}

Author(s):

Wüthrich, Kurt

Publication date:

1987

Permanent link:

https://doi.org/10.3929/ethz-b-000423008

Rights / license:

In Copyright - Non-Commercial Use Permitted

Originally published in:

Quarterly Reviews of Biophysics 19(1-2), https://doi.org/10.1017/S0033583500004005 


\section{Nuclear magnetic resonance - from molecules to man}

\section{KURT WÜTHRICH}

Institut für. Molekularbiologie und Biophysik, Eidgenössische Technische Hochschule-Hönggerberg, CH-8093 Zürich, Switaerland

Initial observations of the physical phenomenon of nuclear magnetic resonance (NMR) date back to the late I940s. In the following two decades high-resolution NMR in solution became an indispensible analytical tool in chemistry, and solid state NMR had an increasingly important role in physics. Some of the potentialities of the method for investigations of complex biological systems had also long been anticipated, and initial experiments with biological specimens were described already 30 years ago. In practice, however, biological applications of NMR have become really attractive only during the last decade, following revolutionary advances in NMR instrumentation and the methodology for their use. NMR projects in biology and medicine now include studies of biomacromolecular structure and function, work on biological membranes, in vivo studies of biochemical processes, and imaging of macroscopic objects. Because of imminent practical applications in medical diagnosis and thanks to extensive coverage by the popular news media, interest in some of the recent developments spreads far beyond the scientific community, making NMR a widely popular field.

NMR applied to biological and medical projects is represented by numerous articles which appeared in Quarterly Reviews of Biophysics during the period 1970-85. In view of the current rapid advances it appears that the time has come to complement these earlier accounts by a broader coverage of areas which have recently either been newly created or largely reshaped. We are in the fortunate position that many of the colleagues who had a leading role in these developments agreed to contribute to this venture, and as a result the special double volume 19/20 includes a collection of ten highly timely reviews on biological NMR.

The early biological applications of NMR techniques were for in vitro investigations on structure and function of biological macromolecules in solution. The first NMR review in Quarterly Reviews of Biophysics by M. Cohn (1970) describes relaxation enhancement techniques with paramagnetic metal ions, which were already used before the development of instrumentation enabling informative direct observation of macromolecular species. Several subsequent accounts describe high resolution NMR experiments which rely in different ways on resolution enhancement through the presence of paramagnetic centers in the 
systems studied, e.g. by introduction of extrinsic spin labels (McConnell \& McFarland, 1970) or paramagnetic metal ions (Morris \& Dwek, 1977), or by using intrinsic paramagnetic metal ions in studies of haemoproteins (Shulman et al. 1975; Senn \& Wüthrich, 1985) and non-haem-iron proteins (Sands \& Dunham, 1975). During the past five years the approach for studies of biopolymers has been dramatically changed by the availability of high magnetic fields enabling experiments at ${ }^{1} \mathrm{H}$ frequencies up to $600 \mathrm{MHz}$, two-dimensional $\mathrm{NMR}$, and new strategies for obtaining resonance assignments and NMR parameters which can be directly related to molecular structures (Wüthrich, 1986). As a result, detailed investigations of diamagnetic proteins and nucleic acids are now feasible, and NMR has become the first technique capable of three-dimensional protein structure determination in non-crystalline environments. Five reviews in this special double volume of Quarterly Reviews of Biophysics are devoted to this theme. R. H. Griffey and A. G. Redfield survey novel heteronuclear NMR experiments for studies of proteins and nucleic acids, W. Braun describes mathematical techniques for protein structure determination from NMR data, G. Giessner-Prettre and B. Pullman discuss quantum-mechanical calculations of chemical shifts in nucleic acids, and two papers by D. J. Patel and by B. R. Reid survey the present state of NMR investigations with nucleic acids. This list does not explicitly include the use of NMR for investigating dynamic properties of biopolymer structures, since this aspect has been superbly covered in two very recent reviews (Wagner, 1983; Englander \& Kallenbach, 1984).

Special NMR techniques have for some time been applied for investigations of the liquid crystal-like states of biological membranes (Seelig, 1 977; Wennerström \& Lindblom, 1977; Seelig \& Seelig, 1980). Experiments which can be used to study ion binding with biopolymers in solution as well as with membranes and biological tissues are now reviewed by S. L. Forsén, T. Drakenberg and H. Wennerström. Decisive progress has also been made with solid state NMR, as is exemplified in a paper by S. J. Opella, P. L. Stewart and K. G. Valentine on structual studies of proteins.

In vivo NMR investigations of intact cells and intact animal and human bodies are of very recent origin, and within an astonishingly short period of time they have become established techniques in biological research as well as in medical diagnosis. In vivo NMR spectroscopy carries great promise for non-invasive studies of metabolic pathways and kinetic processes in living organisms, as is described in two recent Quarterly Reviews of Biophysics articles (Alger \& Shulman, 1984; Deslauriers et al. 1985) and in a paper by K. M. Brindle and I. D. Campbell contained in this special double volume. $N M R$ imaging uses different principles for obtaining pictures of macroscopic objects, notably of interior parts of living human bodies. A review by R. R. Ernst describes the fundamental physical principles underlying this methodology, and A. R. Margulis, H. Hricak and L. Crooks present a report on the present state of medical applications.

Clearly, the collection of NMR reviews in this double volume covers a wide range of topics. In addition to describing the present state of biological and medical NMR, they also present a basis for further advances in the future. 


\section{REFERENCES}

Alger, J. R. Shulman, R. G. (1984). NMR studies of enzymatic rates in-vitro and in-vivo by magnetization transfer. $Q$. Rev. Biophys. 17, 83-124.

CoнN, M. (1970). Magnetic resonance studies of enzyme-substrate complexes with paramagnetic probes as illustrated by creatine kinase. $Q$. Rev. Biophys. 3, 61-89.

Deslauriers, R., Geoffrion, Y., Butler, K. W. \& Smith, I. C. P. (1985). Magnetic resonance studies of the pathophysiology of murine malaria. $Q$. Rev. Biophys. 18, 65-110.

Englander, S. W. \& Kallenbach, N. R. (1984). Hydrogen exchange and structural dynamics of proteins and nucleic acids. $Q$. Rev. Biophys. 16, $521-655$.

McConnell, H. M. \& McFarLand, B. G. (1970). Physics and chemistry of spin labels. Q. Rev. Biophys. 3, 91-136.

MORRIS, A. T. \& DWEK, R. A. (1977). Some recent applications of the use of paramagnetic.centres to probe biological systems using nuclear magnetic resonance. $Q$. Rev. Biophys. 10, $421-484$.

Sands, R. H. \& Dunham, W. R. (1 975). Spectroscopic studies on two-iron ferredoxins. Q. Rev. Biophys. 7, 443-504.

Seelig, J. (1977). Deuterium magnetic resonance: theory and application to lipid membranes. $Q$. Rev. Biophys. ro, 353-418.

Seelig, J. \& Seelig, A. (1980). Lipid conformation in model membranes. $Q$. Rev. Biophys. 13, 19-61.

SENN, H. \& WüTHRICh, K. (1985). Amino acid sequence, haem-iron co-ordination geometry and functional properties of mitochondrial and bacterial c-type cytochromes. Q. Rev. Biophys. 18, I I I-134.

Shulman, R. G., Hopfield, J. J. \& Ogawa, S. (1975). Allosteric interpretation of haemoglobin properties. $Q, R e v$. Biophys. 8, 325-420.

WAGNER, G. ( 1983 ). Characterization of the distribution of internal motions in the basic pancreatic trypsin inhibitor using a large number of internal NMR probes. $Q$. Rev. Biophys. 16, 1-57.

Wennerström, H. \& LindBlom, G. (1977). Biological and model membranes studied by nuclear magnetic resonance of spin one half nuclei. $Q$. Rev. Biophys. 10 67-96.

Wüthrich, K. (1986). NMR of Proteins and Nucleic Acids, New York: Wiley. 